\title{
Kerfless exfoliated thin crystalline Si wafers with Al metallization layers for solar cells
}

\author{
Raphael Niepelt, ${ }^{\text {a) }}$ Jan Hensen, and Verena Steckenreiter \\ Department of Photovoltaics, Institute for Solar Energy Research Hamelin (ISFH), D-31860 Emmerthal, Germany \\ Rolf Brendel \\ Department of Photovoltaics, Institute for Solar Energy Research Hamelin (ISFH), D-31860 Emmerthal, Germany; \\ and Institut für Festkörperphysik, Leibniz Universität Hannover, D-30167 Hannover, Germany
}

Sarah Kajari-Schöder

Department of Photovoltaics, Institute for Solar Energy Research Hamelin (ISFH), D-31860 Emmerthal, Germany

(Received 4 June 2015; accepted 25 September 2015)

\begin{abstract}
We report on a kerfless exfoliation approach to further reduce the costs of crystalline silicon photovoltaics making use of evaporated $\mathrm{Al}$ as a double functional layer. The $\mathrm{Al}$ serves as the stress inducing element to drive the exfoliation process and can be maintained as a rear contacting layer in the solar cell after exfoliation. The 50-70 $\mu \mathrm{m}$ thick exfoliated Si layers show effective minority carrier lifetimes around $180 \mu$ s with diffusion lengths of 10 times the layer thickness. We analyze the thermo-mechanical properties of the Al layer by x-ray diffraction analysis and investigate its influence on the exfoliation process. We evaluate the approach for the implementation into solar cell production by determining processing limits and estimating cost advantages of a possible solar cell design route. The Al-Si bilayers are mechanically stable under processing conditions and exhibit a moderate cost savings potential of 3-36\% compared to other c-Si cell concepts.
\end{abstract}

\section{INTRODUCTION}

Compared to semiconductor microelectronics, the value added per silicon wafer in crystalline silicon (c$\mathrm{Si})$ photovoltaics (PV) is comparatively low. Thus, the wafer production still accounts for about $30 \%$ of the total costs of a $\mathrm{Si}$ solar cell module. ${ }^{1}$ At the same time the price of the polysilicon feedstock, which accounts for half of the wafer costs, is expected to stabilize after a long-lasting drop in prices during the last years. ${ }^{2}$ Accordingly, the amount of Si used per cell has to be reduced to further diminish wafering costs, which is key for further cost reductions in PV specified by the price learning curve. ${ }^{1}$ Besides handling limits, the lowest achievable Si consumption is limited by the kerf loss that standard and advanced wire-saw wafering techniques are inevitably accompanied by Kerfless techniques for the production of silicon wafers aim to overcome this constraint and can thus make a substantial contribution to the PV module price reduction.

During the last decades, several approaches for kerfless wafering have been developed. Many of them are based

\footnotetext{
Contributing Editor: Don W. Shaw

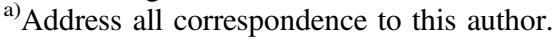

e-mail: niepelt@isfh.de

This paper has been selected as an Invited Feature Paper.

DOI: $10.1557 /$ jmr.2015.309
}

on the introduction of a weaker release layer into a thick solid wafer that can act as a determined breaking point during the lift-off of an upper layer of high quality crystalline silicon. The release layer can be generated below the surface of a high-quality silicon wafer, for instance by implantation of hydrogen ions in the Smart$\mathrm{Cut}^{3}$ and PolyMax ${ }^{4}$ processes or by electrochemically etching in the macroporous silicon process. ${ }^{5}$ In other approaches the release layer is produced on top of the silicon substrate, followed by an epitaxially grown highquality crystalline silicon layer on top, which can be detached afterward. Examples include porous silicon ${ }^{6}$ and $\mathrm{CaF}_{2}$ (Ref. 7) acting as release layers.

The lift-off of a thin crystalline silicon film without the need of a weakened release layer was firstly described by Tanielian in $1985^{8}$ and recently revisited. ${ }^{9-13}$ Here, an adhesive stressor layer on top of a thicker silicon substrate is used to induce the exfoliation of a thin substrate portion. The cracking path follows a trajectory with minimized shear components, resulting in the lift-off of a layer with constant thickness. The theory behind this effect is described in the work of Hutchinson and Suo. ${ }^{14}$

In the "Stress induced Lift-off Method" (SLIM-cut) by Dross et al. ${ }^{9}$ this layer is made of screen-printed metal paste. Stress is induced owing to a mismatch of the coefficients of thermal expansion (CTE) during firing. During the "Controlled Spalling Technology" process by Bedell et al. a stressor layer that is sputter-deposited and 
exhibits a certain amount of tensile stress is combined with an external force applied to an additional handling layer to induce exfoliation. ${ }^{10,11}$ The "Semiconductor On Metal" (SOM) process by Rao et al. makes use of an electrochemically deposited metal layer and thermally induced stresses. ${ }^{12}$ With this process, exfoliated crystalline silicon wafers up to 8 inch in diameter were demonstrated. ${ }^{15}$

A key requirement for the use of spalled silicon layers for solar cells is the preservation of the high electronic quality of the silicon material. The material must not degrade to an efficiency-limiting level during the lift-off process, where the material is exposed to enormous mechanical forces with stresses up to several hundred $\mathrm{MPa}$. Masolin et al. identified near-surface hole traps in exfoliated silicon layers by measuring deep-level transient spectroscopy and electron-spin resonance. Etching off $4.5 \mu \mathrm{m}$ of material from the cracked surface side completely removed these defects. ${ }^{16}$ Martini et al. reached minority carrier lifetimes of $461 \mu$ s on a 100 $\mu \mathrm{m}$ thick foil of $1 \Omega \mathrm{cm}$ n-type material. ${ }^{17}$ Measuring quasi-steady-state photoconductance $(\mathrm{QSSPC})^{18}$ on freestanding exfoliated silicon films, Saha et al. found no degradation of the bulk carrier lifetime compared to the parent substrate before lift-off and showed a solar cell produced from a $25 \mu \mathrm{m}$ thick exfoliated SOM silicon layer with nickel rear contact and an efficiency of $14.9 \%$ on a small area. ${ }^{19}$ These results are encouraging for using spalled layers as solar cell absorber materials.

Different stressor layer materials have been used for the exfoliation of thin foils of crystalline $\mathrm{Si}$ so far, including sputtered or electrodeposited $\mathrm{Ni}^{10-12}$ and $\mathrm{Ni}-\mathrm{Cr},{ }^{8}$ screen-printed metal paste, ${ }^{9}$ glued metal stripes, ${ }^{20}$ and polymers. ${ }^{17,21}$ Within this paper, we present exfoliated silicon foils that were produced using an evaporated $\mathrm{Al}$ film as stressor layer. The use of a metal shows a distinct advantage for photovoltaic applications: To reduce the wafering costs it is preferable not to remove the stressor layer after lift-off but to use it as a functional layer. A metallic layer can act as a rear contact electrode in the solar cell. Therefore the rear side of the solar cell is processed before applying the stressor and rear contact layer. After lift-off, the solar cell frontside can be processed. As an additional benefit, the metal layer can act as a mechanical support for the brittle $\mathrm{Si}$ layer during processing. We dub our bilayers MEMOfoils, where MEMO stands for MEtal supported MOnocrystalline silicon. We use $\mathrm{Al}$ from a physical vapor deposition as a stressor and supporting layer. Al is inexpensive, lightweight, and already well-established as a solar cell material. Stress in the layer is generated during thermal cycling owing to different CTEs in the wafer and the metal. The difference of one order of magnitude in CTE between the two materials (Al: $23.1 \times 10^{-6} \mathrm{~K}^{-1}$ vs. Si: $2.6 \times 10^{-6} \mathrm{~K}^{-1}$ at room temperature $)^{22,23}$ allows for significant thermal stresses and therefore exfoliation at moderate temperatures below $200{ }^{\circ} \mathrm{C}^{24}$ This is desired, as the number of defects in the spalled silicon layer is expected to rapidly increase if the brittle-ductile transition temperature of silicon at $729{ }^{\circ} \mathrm{C}$ is exceeded during exfoliation. $^{10,23}$

This paper discusses the conceptual advantages of this material system for kerfless wafering of solar cells. We give an overview of the foil properties and the potential for solar cells. We investigate the stressor layer properties and discuss the conditions that lead to successful exfoliation of suitable foils. We describe a module concept to integrate the thin MEMO bilayers into solar modules. Finally we discuss the conditions for successful integration of the layers, namely the mechanical stability of the bilayers under elevated temperatures, which defines the applicable processing conditions, and the estimated achievable price advantages over conventional c-Si module concepts by conducting a detailed cost estimation.

\section{SAMPLE PREPARATION, EXFOLIATION, AND ELECTRONIC PROPERTIES OF MEMO-LAYERS}

To obtain a smooth and homogeneous exfoliated $\mathrm{Si}$ surface we use directed cooling for the lift-off. The process flow is schematically shown in Fig. 1. We use an ATON 600 in-line evaporation system from Applied Materials (Alzenau, Germany) ${ }^{25}$ to deposit the 40-120 $\mu \mathrm{m}$ thick $\mathrm{Al}$ stressor layers on a $700 \mu \mathrm{m}$ thick $\mathrm{Si}$ substrate that was passivated with an $\mathrm{Al}_{2} \mathrm{O}_{3}-\mathrm{SiN}_{x}$-stack. Subsequently we create a laser notch at the side of the substrate that acts as the crack initiating site and helps to guide the exfoliation process. The setup for the exfoliation process is sketched in Fig. 2(a). We mount the sample above cooling bath and heat it up by a halogen

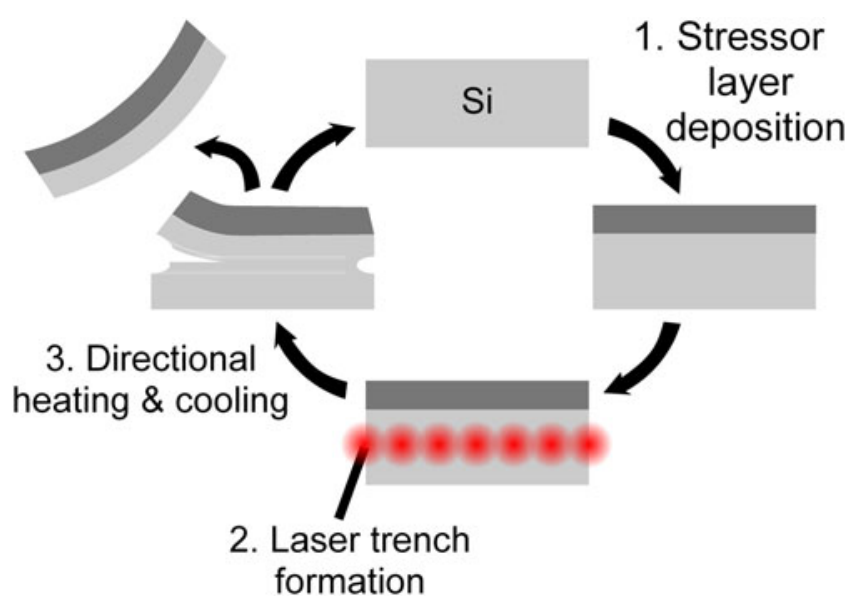

FIG. 1. Metal-supported direct exfoliation process: A metal stressor layer is deposited on the starting wafer. Then, a laser notch is created at the wafer side. Finally, thermal treatment is used to induce mismatch stress in the metal-Si bilayer that leads to exfoliation of a thin Si film. 


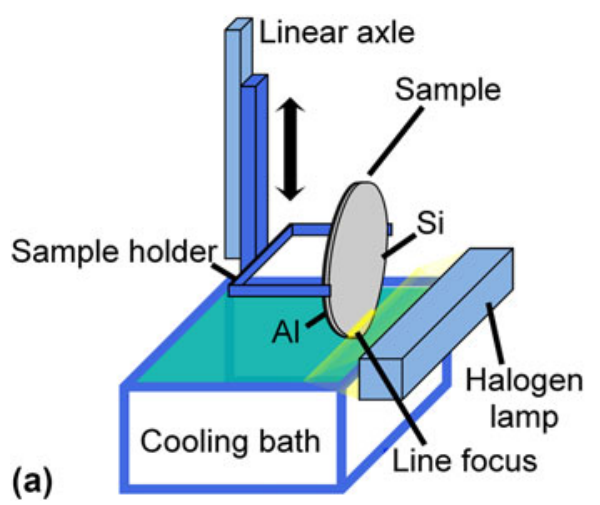

FIG. 2. (a) Setup for directional heating and cooling. ${ }^{24}$ (b) Exfoliated Si foil after Al removal. (c) Profilometer scans across the sample measured along the lines indicated in (b). Pictures (c) and (b) are reprinted from Ref. 26.

lamp, which leads to compressive stress in the metal layer. Afterward we cool the sample by immersing it into the bath to induce tensile stress and therefore enable spalling: the tensile stress inside the metal layer leads to tensile stress along the $\mathrm{Si}$ edge and a high stress intensity at the tip of the laser notch. At a certain stress level, the fracture toughness of the $\mathrm{Si}$ is overcome and a crack starts to grow from the notch across the sample. To obtain a smooth cracked surface we have to avoid the development of multiple crack fronts. ${ }^{10} \mathrm{We}$ secure this by the geometry of the exfoliation setup: the vertically immersed sample is directionally cooled down from one side to the other. In that way the requirements for spontaneous spalling are always only fulfilled within a confined area of the sample and the expansion of the crack front can be controlled. ${ }^{27}$ Additionally, the geometry of the setup results in the creation of a region of locally enhanced cooling and strain rates that lead to locally enhanced stresses in the Al layer, adding another level of control. More details on the exfoliation process and the temperature dynamics therein are given in the reference by Hensen et al. ${ }^{24}$

We use two different $\mathrm{Al}$ sources for the stressor layers: high-purity (99.98\%) Al 99.98 and lower purity Al 99.7. The choice of $\mathrm{Al}$ has an influence of the applicable stressor layer thicknesses. With Al 99.98 we need at least $80 \mu \mathrm{m}$ thick stressor layers for exfoliation. For Al 99.7, also thinner stressor layers down to $40 \mu \mathrm{m}$ thickness can be used, although there is still room for optimization in terms of process stability. We get the best control over the process with $120 \mu \mathrm{m}$ thick Al 99.98 layers. In this case we obtain $50-80 \mu \mathrm{m}$ thick silicon foils by stress induced lift-off from the $700 \mu \mathrm{m}$ thick parent wafer (FZ, $0.5 \Omega \mathrm{cm}$ p-type). ${ }^{26}$ Figures 2 (b) and 2(c) show an exfoliated sample after $\mathrm{Al}$ removal and the respective Profilometer scans of the surface. ${ }^{26}$ The sample appears very smooth over almost the entire cracked silicon surface with some rougher areas at the outer regions. Lifetime measurements at $\mathrm{Al}_{2} \mathrm{O}_{3}$-passivated layers via spatially resolved infrared lifetime mapping (ILM) ${ }^{28}$ [Fig. 3(b)] reveal an effective minority carrier lifetime up to $182 \mu$ s average at an estimated carrier concentration of $\Delta n=1.1 \times 10^{15} \mathrm{~cm}^{-3}$ and minority carrier diffusion lengths in the spalled layers of 10 times the layer thickness. ${ }^{26}$ We use QSSPC to estimate the bulk lifetime in the spalled layer at room temperature and obtain a value of $380 \mu \mathrm{s}$, which is 2.5 times lower than the theoretically estimated value of $967 \mu \mathrm{s} .^{29,30}$ Thus, we see some significant degradation of the material in the thin wafer, despite the still excellent effective lifetimes that facilitate the use of the wafer for high-efficiency solar cells. The measurements on the substrate after the lift-off [Fig. 3(d)] reveal little to no degradation of the carrier lifetime due to the exfoliation process. ${ }^{26}$ The line spot with lower lifetimes in Fig. 3(d) is caused by the collision of two crack fronts and can be avoided by using appropriate exfoliation parameters. The results demonstrate that the spalling process with $\mathrm{Al}$ stressor layers is capable of producing thin wafers for highly efficient solar cells without degrading the substrate's electronic quality.

\section{THE AL STRESSOR LAYER}

\section{A. Al yield strength}

Compared to most other metals, pure $\mathrm{Al}$ exhibits low stiffness and yield stress. However, the mechanical properties of Al films are strongly affected by crystal grain size and additives. We investigate the mechanical properties of the evaporated $\mathrm{Al}$ stressor layers by X-ray diffraction (XRD) stress measurements to determine the applicability of these layers for direct exfoliation.

The maximum thermal stress that occurs inside a bilayer of a brittle and a ductile material is governed by the yield strength $\sigma_{\mathrm{y}}$ of the ductile material. If the stress level inside the ductile layer reaches $\sigma_{\mathrm{y}}$ the material starts to flow and deforms plastically. Thus, the $\mathrm{Al}$ yield strength $\sigma_{\mathrm{y}, \mathrm{Al}}$, is the most important measure for the applicability of an evaporated Al layer as stressor layer. The exact 


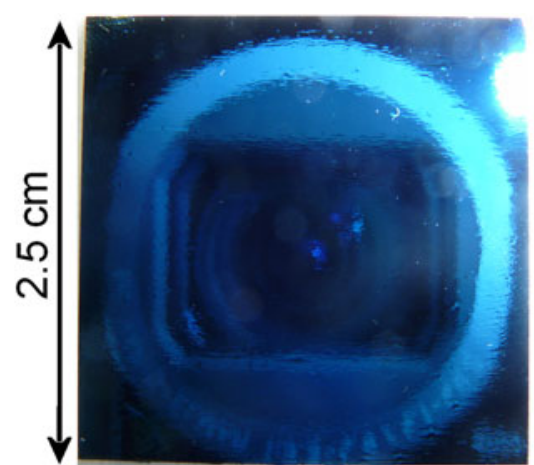

(a)

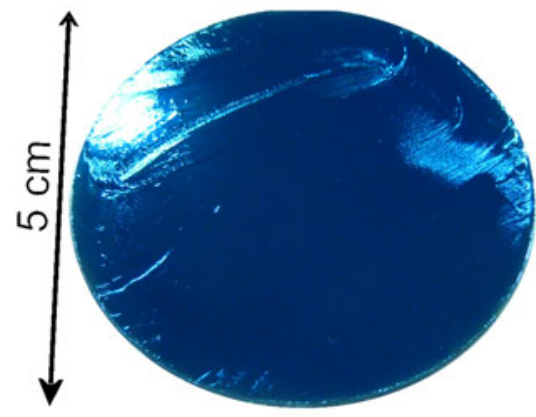

(c)

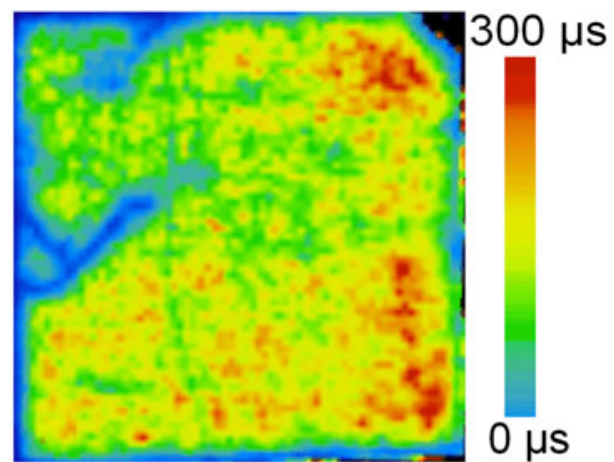

(b)

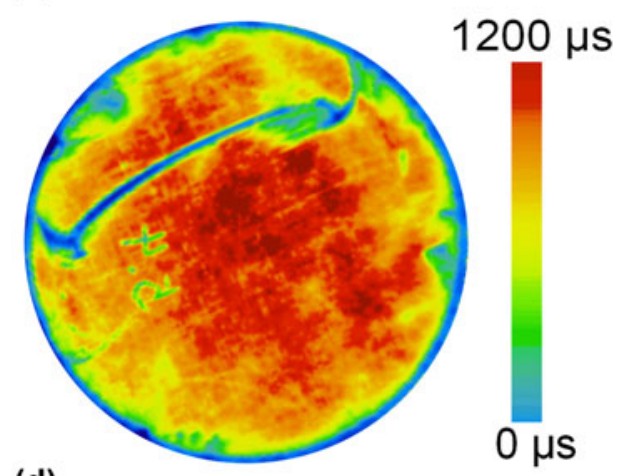

(d)

FIG. 3. Lifetime measurements on exfoliation samples. (a) Photograph of the cleaved side of a $6.25 \mathrm{~cm}^{2}$ exfoliated Si layer; (b) DynILM lifetime mapping of the layer in (a) after lift-off, $\mathrm{KOH}$ etching, and passivation with $\mathrm{Al}_{2} \mathrm{O}_{3}$. The effective lifetime averaged over the whole sample is $159 \mu \mathrm{s}$ at an estimated carrier concentration of $\Delta n=1.1 \times 10^{15} \mathrm{~cm}^{-3}$ and $182 \mu$ s at an estimated carrier concentration of $\Delta n=1.5 \times 10^{15} \mathrm{~cm}^{-3}$ if the upper left quarter of the sample is excluded from averaging. (c) Photograph of the cleaved side of a $2^{\prime \prime}$-diameter Si wafer substrate after layer exfoliation; (d) ILM lifetime mapping after lift-off, KOH etching, and passivation. The effective lifetime averaged over the central $2 \times 2 \mathrm{~cm}^{2}$ area is $1105 \mu \mathrm{s}$ at an estimated carrier concentration $\Delta n=1.1 \times 10^{15} \mathrm{~cm}^{-3}$. Pictures are reprinted from Ref. 26.

value of $\sigma_{\mathrm{y}, \mathrm{Al}}$, is strongly Al-purity-level-dependent, and thus in our evaporated layers not only coupled to the purity of the Al source, but also the actual vacuum level of our ATON 600 evaporation tool during layer deposition. To measure values of $\sigma_{\mathrm{y}, \mathrm{Al}}$ of the evaporated Al layers we conduct XRD stress measurements. ${ }^{31}$ Figure 4(a) shows the stress we measure at the $\mathrm{Al}$ surface of Al-Si bilayers during thermal cycling between room temperature and $150{ }^{\circ} \mathrm{C}$. The dark blue squares belong to a bilayer test sample consisting of $10 \mu \mathrm{m}$ high-purity $\mathrm{Al}$ 99.98 and $150 \mu \mathrm{m} \mathrm{Si}$. The light blue points are obtained from a $40 \mu \mathrm{m}$ thick Al 99.7 layer on top of a $700 \mu \mathrm{m}$ thick Si sample, which is the thinnest Al type and layer thickness combination we could use for exfoliation so far. The penetration depth of the x-rays varies from 6 to $31 \mu \mathrm{m}$ during the measurements. We can assume the measured values as average residual stress values inside the Al layers.

The stress-strain-relation of the high-purity Al 99.98 shows a hysteresis behavior which is caused by plastic deformation. The hysteresis is highlighted in Fig. 4(b). It can be described by a bilinear stress model ${ }^{32}$ with a negative strain hardening coefficient during heating and a positive coefficient during cooling. The interesting half of the cycle for the exfoliation process is the cooling half cycle, where tensile stress is built up in the Al layer. This also leads to tensile stress at the $\mathrm{Si}$ edge of the sample, fostering crack initiation if high enough. We conduct linear fits on the elastic and plastic region of the cooling half-cycle and obtain the Young's modulus $E_{\mathrm{Al}}=70 \mathrm{GPa}$ in the elastic regime. The yield strength $\sigma_{\mathrm{y}, \mathrm{Al}}$ can be determined from the graph as the stress value where the layer leaves the elastic regime. Because of the temperature dependency of $\sigma_{\mathrm{y}, \mathrm{Al}}$, different values have to be considered for the heating and the cooling half-cycle, namely $\sigma_{\mathrm{y}, \mathrm{Al} \text {,heating }}=-50 \pm 5 \mathrm{MPa}$ and $\sigma_{\mathrm{y}, \mathrm{Al} \text {,cooling }}=30 \pm 5 \mathrm{MPa}$. The values cannot be used as general values for $\mathrm{Al}$ layers as they indeed depend on the level of absolute temperature during the thermal cycling. After leaving the elastic regime during cooling, the stress in the layer is further increased by plastic hardening with the hardening coefficient $H_{\mathrm{Al}}=30 \mathrm{GPa}$. The maximum stress value in our measurement is reached at room temperature, where $\sigma_{\max , 99.98} \approx 80 \mathrm{MPa}$.

For the Al 99.7 layer, which is expected to exhibit a higher yield strength, $\sigma_{\mathrm{y}, \mathrm{Al} \text {,heating }}$ proves to be comparable 

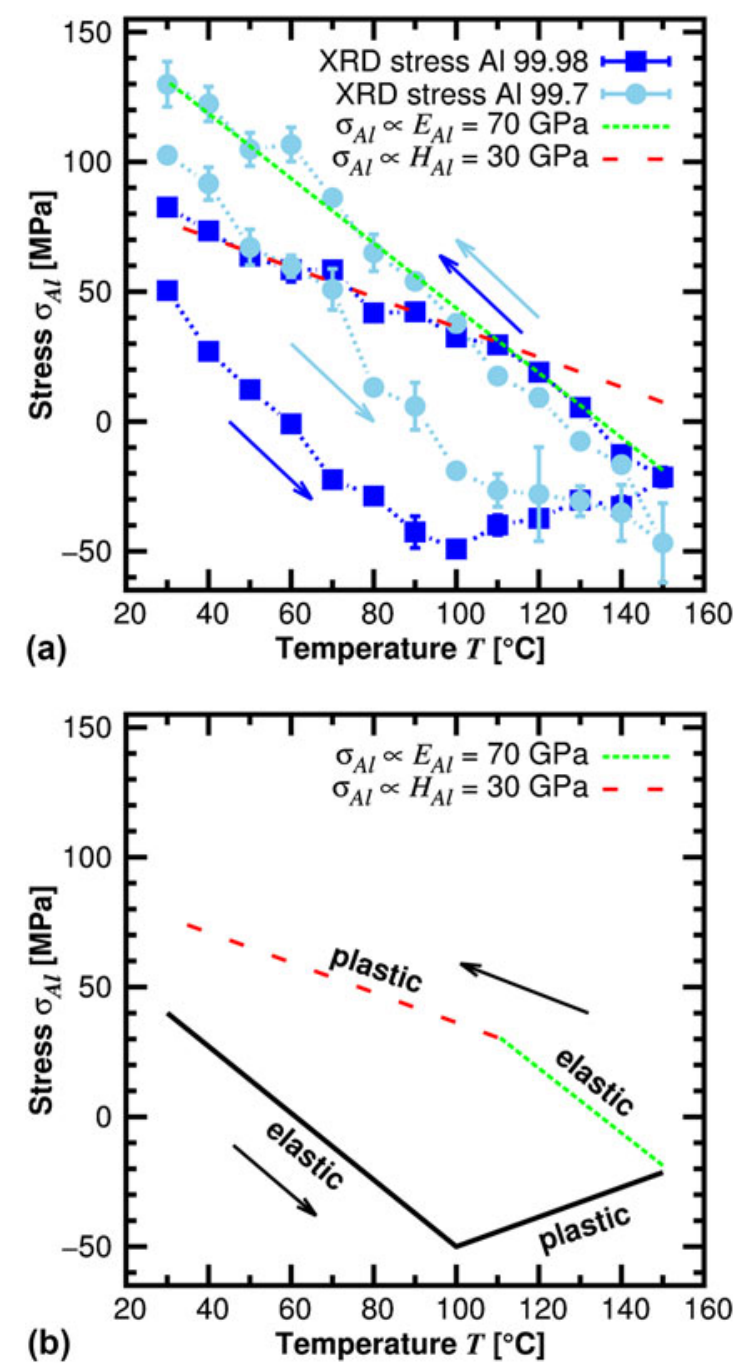

FIG. 4. (a) XRD stress measurements of a high-purity Al layer and an Al 99.7 layer on thick Si substrates during thermal cycling. Lines show linear fits to the elastic (green) and plastic (red) deformation regime of the high-purity layer during cooling. (b) Visualization of the elastic and plastic deformation regimes of the high-purity Al layer during thermal cycling.

to the high-purity layer. During cooling however, the lower purity $\mathrm{Al}$ shows a nearly linear stress-temperature relation over the whole investigated cooling range from 150 to $30{ }^{\circ} \mathrm{C}$ and thus no plastic flow, pointing to

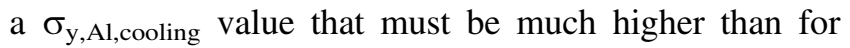
the high-purity $\mathrm{Al}$. The maximum stress value at room temperature is $\sigma_{\max , 99.7} \approx 130 \mathrm{MPa}$.

\section{B. Minimum Al layer thickness for exfoliation}

From the maximum stress level it is possible to derive a lower limit for the thickness of the stressor layer for a successful lift-off. Figure 5 displays the minimum stress inside the $\mathrm{Al}$ that is needed to induce crack propagation for exfoliation, calculated using the steady state cracking model of Hutchinson and Suo ${ }^{14}$ :

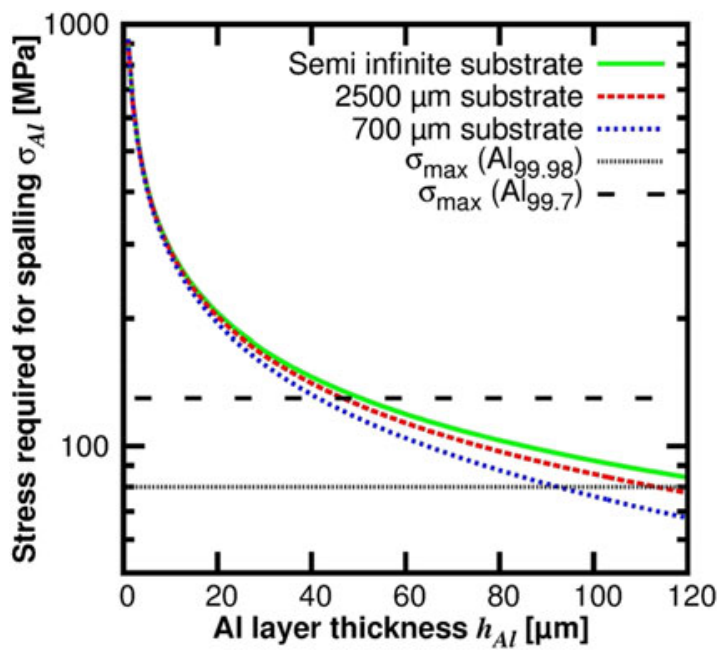

FIG. 5. Minimum stress in the Al layer that is required for successful bilayer exfoliation on $\mathrm{Si}$ substrates of different thicknesses in the steady-state-cracking model. The Si fracture toughness is assumed as $0.75 \mathrm{MPa} \mathrm{m}^{1 / 2}$.

in order for a crack to propagate parallel to the surface and thus successfully exfoliate a $\mathrm{Si}$ layer, the opening mode stress intensity factor $K_{\mathrm{I}}$ at the crack initiating site has to exceed the $\mathrm{Si}$ fracture toughness $K_{\mathrm{IC}}$. As $\mathrm{Si}$ is strongly anisotropic, values for $K_{\mathrm{IC}}$ depend on the crack orientation inside the crystal. Literature values are widely spread. In a recent publication, Masolin et al. analyzed the values reported for the low-index breaking planes in more detail and suggested a value of $0.75 \mathrm{MPa} \mathrm{m}{ }^{1 / 2}$ for a crack along a $\{100\}$-plane, ${ }^{23}$ which is the cleavage plane in our directed cooling process. We calculate the stress value in the Al layer for which $K_{\mathrm{I}}=K_{\mathrm{IC}}=0.75 \mathrm{MPa} \mathrm{m}{ }^{1 / 2}$. This value corresponds to the minimum actual stress in the $\mathrm{Al}$ layer that is needed to let the crack propagate and is displayed in Fig. 5 as a function of Al stressor layer and Si substrate thickness. Please note that the model in Ref. 14 uses the so called equivalent edge load or thermal misfit stress that has to be converted to the actual biaxial stress in the bilayer to compare the model to experimental stress data. ${ }^{33}$ These corrections are already applied to the data in Fig. 5.

We learn from Fig. 5 that the stress needed for crack propagation grows with increasing substrate thickness and decreasing Al layer thickness. The gray and black dashed lines in Fig. 5 mark the maximum stress values of 80 and $130 \mathrm{MPa}$ that were obtained from the XRD measurement of the high-purity and low-purity $\mathrm{Al}$ layers, respectively. The maximum applicable stress values define a minimum stressor layer thickness that we have to ensure for a successful exfoliation process. As the flow stress strongly depends on temperature and strain rate ${ }^{34,35}$ the values from the XRD measurement might not be the correct absolute stress values to define a hard limit. 
However, the thinnest high-purity Al layer that we could use for a successful exfoliation process had a thickness of $100 \mu \mathrm{m}$, in accordance with the graph in Fig. 5. With layers from the lower purity $\mathrm{Al}$ evaporation source (Al 99.7) we were indeed able to exfoliate $\mathrm{Si}$ with thinner Al stressor layers down to $40 \mu \mathrm{m}$ thickness. Thus, our results are consistent with the theory.

The strength of $\mathrm{Al}$ can be adapted to even higher values by selectively adding different alloying components. With the addition of $1 \% \mathrm{Si}$ or $0.5 \% \mathrm{Si}$ and $0.5 \%$ $\mathrm{Cu}$ for example, the flow stress in $\mathrm{Al}$ films is enhanced to 211 and $300 \mathrm{MPa},{ }^{36}$ respectively. However, when changing to an $\mathrm{Al}$ alloy, besides the mechanical properties of the layer also the chemical composition has to be considered to exclude undesired contamination of the solar cell absorber and thus a lowered solar cell performance owing to the choice of the $\mathrm{Al}$ stressor layer. Thus, exfoliation with thin $\mathrm{Al}$ stressor layers is possible, but a suitable $\mathrm{Al}$ alloy has to be selected.

We consider an Al thickness of $40 \mu \mathrm{m}$ necessary for a working exfoliation process and take this value as a base for the following considerations in this paper. For the exfoliation from a $2500 \mu \mathrm{m}$ thick substrate with a $40 \mu \mathrm{m}$ thick $\mathrm{Al}$ layer for example, theoretically a stress level of $142 \mathrm{MPa}$ in the $\mathrm{Al}$ layer would be sufficient.

\section{Al layer thickness and Al/Si thickness ratio}

One important aspect for the cost-effectiveness of the MEMO-process and other exfoliation schemes is the material consumption for the stressor and the exfoliated layer. While the stressor layer thickness has a lower limit defined by the strength of the material, the thickness of the exfoliated Si layer also depends on the $\mathrm{Al}$ stressor layer thickness as well as the mechanical properties of both materials. The expected thickness ratios can be calculated following the steady-statecracking theory by Hutchinson and Suo. ${ }^{14}$ In Fig. 6 the theoretical exfoliated Si layer thickness $h_{\mathrm{Si}}$ is plotted against the Al stressor layer thickness $h_{\mathrm{Al}}$ for three different Si substrate thicknesses i.e., 700, $2500 \mu \mathrm{m}$ and one assumed as semi-infinite. We find that an $\mathrm{Al}$ thickness of $40 \mu \mathrm{m}$ is sufficient to obtain a Si layer thickness of $50 \mu \mathrm{m}$, which is convenient for a highefficiency solar cell from p-type $\mathrm{Si}^{37,38}$ if the parent wafer is thick enough. A decreasing substrate thickness lowers the thickness of the spalled layer if the stressor layer is unchanged, accompanied by an increasing dependence on the substrate thickness. With the currently used $700 \mu \mathrm{m}$ thick parent wafers, the $\mathrm{Al} / \mathrm{Si}$-ratio is comparably high. Thus, we propose the use of thicker parent wafers, or alternatively to bond the substrate wafers to a stiff material to make them mechanically thick even when the Si thickness falls below a few hundred micrometers.

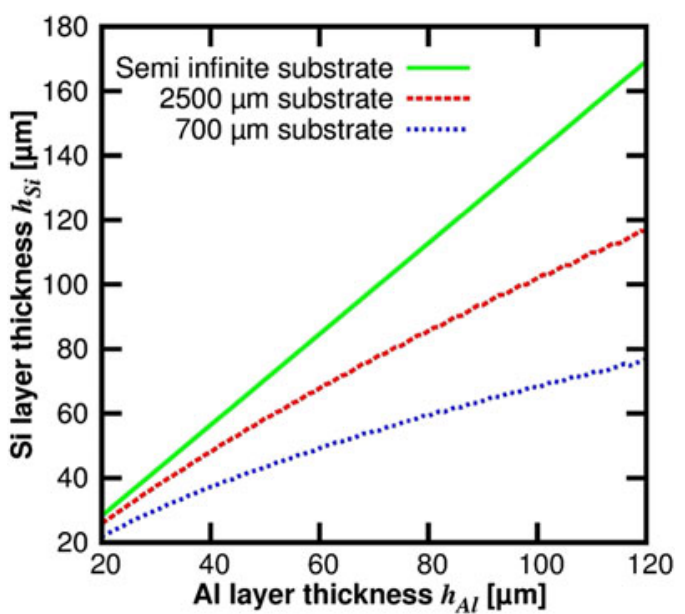

FIG. 6. Si layer thickness (cracking depth) plotted against Al stressor layer thickness for bilayer exfoliation in the steady state cracking model calculated for three different substrate thicknesses.

An $\mathrm{Al}$ thickness of $40 \mu \mathrm{m}$ and an $\mathrm{Al} / \mathrm{Si}$ ratio close to one is much more than is usually deemed acceptable in solar cell manufacturing. However, in those cases the metal only fulfills a single function, forming the electrical contact. In the case of exfoliation, the aspired double function of the exfoliation layer must be considered.

\section{INTEGRATION OF MEMO-BILAYERS INTO PHOTOVOLTAIC SYSTEMS}

For the integration of MEMO-bilayers into commercial solar cells and modules, several issues have to be addressed. If using the metal layer in its double function, the spalled layers are not compatible with standard cell processes. Instead, the use of an alternative processing route with a suitable cell and module concept is necessary. In addition, the thin silicon layers have to withstand the stresses during further processing without failure, and most importantly, following all considerations a reasonable cost advantage for PV modules from the exfoliation process has to exist to motivate the implementation of a novel wafering technique into the solar module supply chain. In the following we will analyze and discuss each of these points, evaluate the underlying causes of the identified limitations and indicate the steps that are necessary to overcome them.

\section{A. Thin-film/wafer hybrid silicon (HySi) technology by module level processing route}

One important aspect of the MEMO concept is the double function of the metal layer that is first used as stressor layer for exfoliation and second as mechanical support and functional layer in the solar cell. While standard solar cell processing cannot be applied to such bilayers, they are compatible with HySi-technology, 
a concept where the front side of $\mathrm{c}-\mathrm{Si}$ solar cells is processed after the rear side is processed on wafer level and the wafers are bonded on a large carrier. ${ }^{39}$ Due to the simultaneous processing this concept allows the application of cost-effective thin film processes at module level. The approach was developed particularly for the processing of very thin absorbers, as the rigid substrate gives an additional mechanical support during the front side processing. Recently, conversion efficiencies of $20 \%$ have been demonstrated with this cell process on wafer-based absorbers. ${ }^{40}$ Due to the difference in CTE the spalled MEMO layers tend to be curved. One option is to flatten the bilayer that is pre-stressed after exfoliation under pressure and bond it to a rigid module substrate. After that, a HySi-like processing route can be applied.

The proposed processing route is schematically depicted in Fig. 7. Prior to the Al stressor layer deposition, the parent wafer surface is (a) passivated with an $\mathrm{Al}_{2} \mathrm{O}_{3}-\mathrm{SiN}_{x}$-stack that includes local contact openings, forming a passivated emitter and rear cell (PERC) type solar cell rear contact structure directly on the thick substrate. After lift-off (b), the curved bilayers are flattened and (c) permanently bonded to a substrate e.g., glass. Now the $\mathrm{Al}$ stressor layer that was used for exfoliation acts as the rear side contact. On the front side of the exfoliated bilayer we deposit an amorphous $\mathrm{Si}(\mathrm{a}-\mathrm{Si} \mathrm{H})$ layer to form a $\mathrm{Si}$ heterojunction $(\mathrm{SHJ})$ cell structure using a plasma enhanced chemical vapor deposition (PECVD) at moderate temperatures, thus compatible with the bonding material at the rear side of the absorber. All processing steps including (d) texturing, (e) forming the a-Si:H-c-SHJ and transparent conductive oxide (TCO) coating, and (f) forming the front contacts are carried out by temperatures below $250{ }^{\circ} \mathrm{C}$.

\section{B. Mechanical stability of MEMO bilayers}

Most solar cell processes are carried out at elevated temperatures. While the temperature range in the above described process flow is already lower than in standard solar cell processes, the MEMO Al-Si bilayer with a $50 \mu \mathrm{m}$ thick Si absorber layer and a $40 \mu \mathrm{m}$ thick $\mathrm{Al}$ contact layer is still experiencing thermally induced stress during cell processing due to the CTE mismatch between the materials. In the following, we analyze the limits in processing conditions, in particular regarding the processing temperature, resulting from the limits in mechanical stability of the bilayer.

Directly after spalling, the Al-Si bilayer is curved. The curvature results from residual stresses inside the bilayer. When the Al layer is removed by wet-chemical etching, the exfoliated $\mathrm{Si}$ foil is completely flat [Fig. 2(b)], indicating that the silicon layer itself is globally stress-free. We observe that the $\mathrm{Si}$ layer is crack-free to the eye after the lift-off process and the aluminum removal. For the HySi process, the $\mathrm{Al}$ remains on the silicon absorber. The mechanically

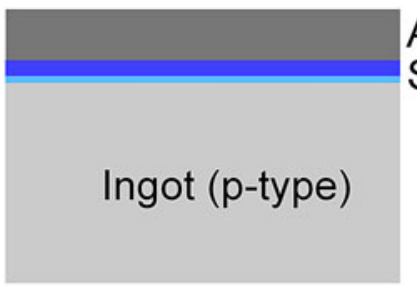

(a)

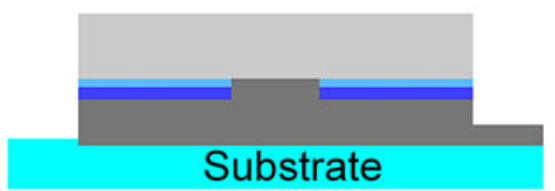

(c)

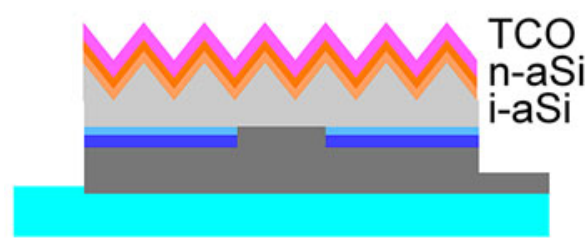

(e)

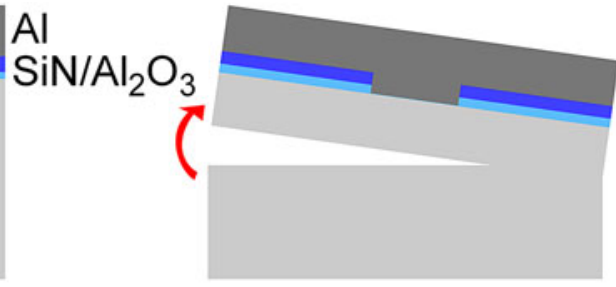

(b)

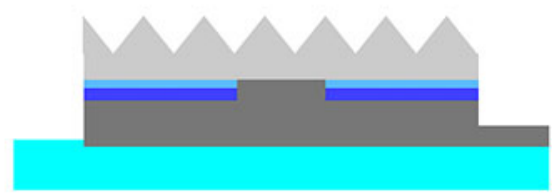

(d)

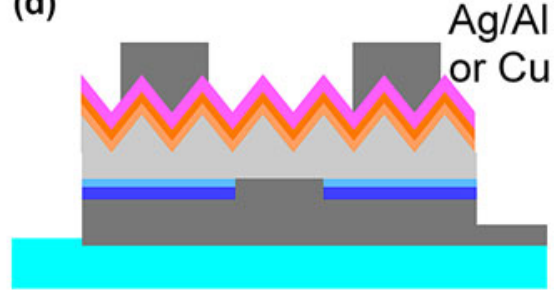

(f)

FIG. 7. Solar cell concept for MEMO bilayers. (a) The rear side of the solar cell is defined on the ingot and then exfoliated (b). (c) The bilayer is bonded to a rigid substrate and subsequently textured (d). (e) A PECVD heterojunction and a sputtered TCO coating complete the sunny side of the cell. (f) Finally, front-side metallization is applied. 
relatively flexible $\mathrm{Al}-\mathrm{Si}$ bilayer is flattened and then encapsulated for further processing.

The encapsulated bilayer is primarily experiencing stress during processing that is induced by the CTE mismatch between the $\mathrm{Si}$ and the $\mathrm{Al}$ layer. Modulesubstrate-induced thermal misfit stresses can also occur, but usually show a lower impact on the strain in the cells than in the encapsulating material. ${ }^{41,42}$ The Al-Si mismatch stress however can cause interface debonding or crack propagation through the Si layer, especially when the surface is textured. An upper temperature limit can be derived following a procedure by $\mathrm{Xu}$ et al. ${ }^{43}$ Here, the bilayer is assumed to be flattened under pressure and bonded to a rigid substrate. Then the stress intensity factor $K$ at the textured surface and the energy release rate $G$ at the Al-Si interface are calculated as a function of processing temperature. These values are compared to the fracture toughness of a textured Si surface and the critical energy release rate $G_{\mathrm{C}}$ of the interface for debonding as naturally given limits that must not be exceeded during handling. In the case of a MEMO-foil with $50 \mu \mathrm{m} \mathrm{Si}$ and $40 \mu \mathrm{m} \mathrm{Al}$, we calculate temperature ranges of $360 \mathrm{~K}$ (fracture toughness) and $165 \mathrm{~K}$ (interface debonding) above room temperature with this method. Not yet included in this evaluation is the plastic behavior of $\mathrm{Al}$ that can lead to a significant underestimation of the interface debonding strength. ${ }^{44}$ Thus, we extend the model by considering the plastic regime in this paper to derive the processing temperature limits with respect to the two failure modes.

The cracking failure mode, which is crack propagation from the Si surface into the bulk, will only occur if the textured $\mathrm{Si}$ surface is exposed to tensile stress. For the bilayer that is flatly bonded to a rigid substrate, this happens during heating, when the $\mathrm{Al}$ is faster expanding than the Si due to its larger CTE. From Fig. 4 we can see that the maximum tensile stress in the Si layer and thus at the textured surface does not depend on the maximum processing temperature but on the yield strength of the $\mathrm{Al}$

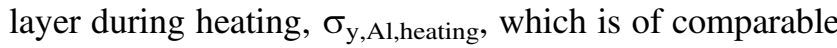
size for both investigated $\mathrm{Al}$ purities. In the case of a MEMO-foil with $50 \mu \mathrm{m} \mathrm{Si}$ and $40 \mu \mathrm{m} \mathrm{Al}$, this $\mathrm{Al}$ yield strength would lead to a tensile stress in the Si layer of $\sigma_{\mathrm{Si} \text { max }}=40 \pm 6 \mathrm{MPa}$ and a maximum stress intensity factor at the textured surface of $K_{\mathrm{I} \text {,tex }}=125 \mathrm{KPa} \mathrm{m}^{1 / 2}$. In Fig. $8, K_{\mathrm{I}, \text { tex }}$ (solid blue line) is plotted against the applied temperature difference $\Delta T$ together with the $\mathrm{Si}$ fracture toughness $K_{\mathrm{IC}} \approx 750 \mathrm{KPa} \mathrm{m}{ }^{1 / 2} \cdot{ }^{23}$ We find that over the whole displayed temperature range $K_{\mathrm{I}, \mathrm{tex}}<K_{\mathrm{IC}}$ and thus the cracking failure mode is not critical for a MEMOlayer with $\mathrm{Al} 99.98$ bonded to a rigid substrate. It can become critical, however, for other $\mathrm{Al}$ alloys. The increasing dotted blue line in Fig. 8 displays the elastic case. If the $\mathrm{Al}$ layer stays in the elastic regime up to processing temperatures of more than $360 \mathrm{~K}$ above room

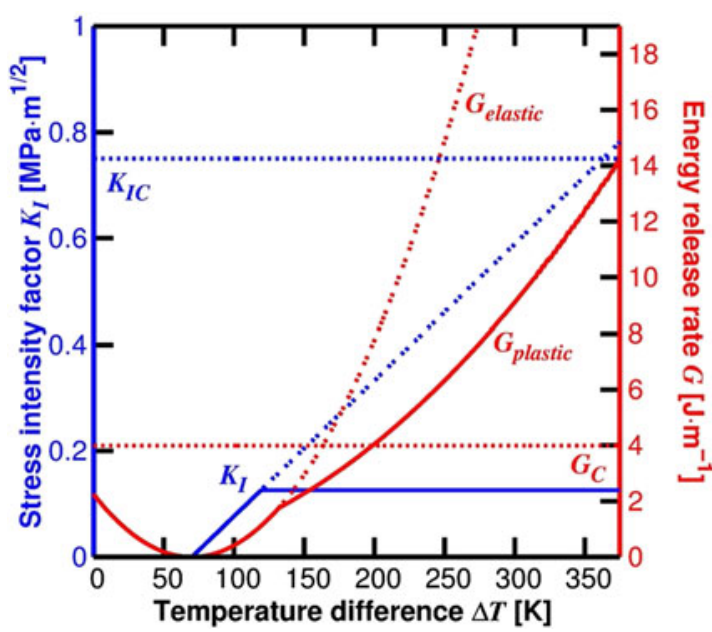

FIG. 8. Stress intensity factor $K_{\mathrm{I}}$ (blue solid line) at the Si surface and energy release Rate $G$ (red solid line) of a MEMO bilayer for temperature difference $\Delta T$ applied during thermal cycling obtained from elastoplastic analysis. Intermittently dotted lines: $G$ and $K_{\mathrm{I}}$ obtained from a fully elastic analysis. Regular dotted lines: Critical Si fracture toughness $K_{\mathrm{IC}}$ and interface toughness $G_{\mathrm{C}}$.

temperature, the limit from the elastic case calculation defines the maximum applicable process temperature. This case applies for $\mathrm{Al}$ alloys with a yield strength above $\sigma_{\mathrm{y}, \mathrm{Al}} \geq 300 \mathrm{MPa}$ at elevated temperatures.

The critical value for the delamination failure mode is the maximum amplitude of the thermally induced stresses in the bilayer. The XRD measurement in Fig. 4(a) shows that the maximum amplitude in both investigated layers is reached during cooling. Thus, we have to investigate the stresses induced during cooling to find a temperature limit. From the stresses $\sigma_{\mathrm{Al}}$ and $\sigma_{\mathrm{Si}}$ in the layers we can then derive the stored potential energy or energy release rate by integrating the strain energy density ${ }^{32}$

$$
G=\frac{1}{2}\left(\int_{0}^{h_{\mathrm{Al}}} \frac{\sigma_{\mathrm{Al}}^{2}(y)}{\bar{E}_{\mathrm{Al}}} \mathrm{d} y+\int_{-h_{\mathrm{Si}}}^{0} \frac{\sigma_{\mathrm{Si}}^{2}(y)}{\bar{E}_{\mathrm{Si}}} \mathrm{d} y\right),
$$

here, $\bar{E}_{i}$ is the effective Young's modulus, which is defined by the Young's modulus $E_{i}$ and Poisson's ratio $v_{i}$ via $\bar{E}_{i}=E_{i} /\left(1-v_{i}^{2}\right)$, of the respective layer with the thickness $h_{i}$, and $y$ is the direction vertical to the surface. To simplify the expression we neglect all curvatureconnected terms as the bilayer is flatly bonded and consider only uniaxial stresses.

At the highest temperature point, the Al layer encounters compressive stress at the magnitude of the yield strength of the material at the elevated temperature, which is named $\sigma_{\mathrm{y}, \mathrm{Al} \text {,cooling }}$ in the following, as it denotes the yield strength value that has to be considered during cooling. Cooling down, the Al will contract elastically, first relieving compressive stress and then building up tensile stress. The lower purity $\mathrm{Al}$ shows no plastic 
deformation behavior during cooling in Fig. 4(a). Thus, we can estimate the temperature limit for interface debonding following the procedure in Ref. 43, where the metal stressor layer is considered elastically deforming. The processing limit is derived by comparing the energy release rate in the bilayer to the critical interface release rate of the interface $G_{\mathrm{C}}$. The debonding limit is set by the temperature $T_{\text {critical }}$ where the energy release rate exceeds the critical energy release rate. Assuming the samples are cooled down to room temperature $T_{\mathrm{R}}$ after processing, this value corresponds to $T_{\text {critical }}=T_{\mathrm{R}}+\Delta T_{\text {critical }}$ with $G\left(\Delta T_{\text {critical }}\right)=G_{\mathrm{C}}$. The critical rate $G_{\mathrm{C}}$ is defined as the energy per area that is needed to split the interface. While actually being a property of the interface, it is practically appraised as the critical strain energy release rate of the material with the lower crack growth resistance, ${ }^{43}$ which is in this case $\mathrm{Si}$, leading to $G_{\mathrm{C}}=K_{\mathrm{IC}, \mathrm{Si}^{2}} / \bar{E}_{\mathrm{Si}} \approx 4 \mathrm{Jm}^{2}$.

However, there are two additional aspects that have to be taken into account here. First, a thin (10-100 nm) dielectric layer is needed between the $\mathrm{Al}$ and the $\mathrm{Si}$ in HySi technology. The critical strain energy release rate of a $\mathrm{SiN}_{x}$ layer on a $\mathrm{Si}$ substrate was determined as only 1.5 $\mathrm{J} / \mathrm{m}^{2}$ and thus we expect such a layer to have a lowering effect on $G_{\mathrm{C}}{ }^{45}$ Second, the plasticity of the Al leads to a converse effect: work that is needed to plastically deform the Al layer actually raises the value of $G_{\mathrm{C}}$, especially when the $\mathrm{Al}$ layer becomes much thicker than the interface itself. ${ }^{45,46}$ We conclude from literature that in MEMO-layers the latter effect at least compensates the first one and can thus assume the critical strain energy release rate to be $G_{\mathrm{C}} \geq 4 \mathrm{~J} / \mathrm{m}^{2}$. Using this value we find the processing limit of the elastic case of $T_{\text {critical }}=165 \mathrm{~K}$ above room temperature for the lower purity $\mathrm{Al}$ layer.

The high-purity Al layer only deforms elastically until the yield strength $\sigma_{\mathrm{y}, \mathrm{Al} \text {,cooling }}$ is reached under tensile stress. The temperature difference $\Delta T_{\mathrm{y}}$ that has been occurred until this point can be obtained from the elastic axial stress expression ${ }^{43}$

$$
\sigma_{\mathrm{Al}}=\frac{\bar{E}_{\mathrm{Si}} h_{\mathrm{Si}}}{\bar{E}_{\mathrm{Al}} h_{\mathrm{Al}}+\bar{E}_{\mathrm{Si}} h_{\mathrm{Si}}} \bar{E}_{\mathrm{Al}}\left(\left(\alpha_{\mathrm{Al}}-\alpha_{\mathrm{Si}}\right) \Delta T-\varepsilon_{0}\right)
$$

where $\alpha_{i}$ is the CTE of the respective material. As the bilayer is assumed to be in the plastic regime before being cooled down, the initial compressive strain $\varepsilon_{0}$ can be written as $\varepsilon_{0}=\sigma_{\mathrm{y}, \mathrm{Al} \text {,cooling }} / \bar{E}_{\mathrm{Al}}$. Then the temperature difference when reaching the yield strain is given as

$$
\Delta T_{\mathrm{y}}=\frac{\sigma_{\mathrm{y}, \mathrm{Al}, \text { cooling }}}{\bar{E}_{\mathrm{Al}}\left(\alpha_{\mathrm{Al}}-\alpha_{\mathrm{Si}}\right)} \frac{\bar{E}_{\mathrm{Al}} h_{\mathrm{Al}}+2 \bar{E}_{\mathrm{Si}} h_{\mathrm{Si}}}{\bar{E}_{\mathrm{Si}} h_{\mathrm{Si}}}
$$

with $\sigma_{\mathrm{y}, \mathrm{Al} \text {,cooling }}=30 \mathrm{MPa}$ this results in $\Delta T_{\mathrm{y}}=45 \mathrm{~K}$. This value is in line with the width of the elastic regime during cooling that can be seen in Fig. 4. The energy release rate of the bilayer corresponding to $\Delta T_{y}$ is $G=0.27 \mathrm{~J} / \mathrm{m}^{2}$. Hence, we can also conclude that we do not expect delamination within the elastic regime of the high-purity $\mathrm{Al}$ layer.

To calculate the energy release rates for interface debonding during the plastic regime $\Delta T>\Delta T_{\mathrm{y}}$, we approximate the stress in the layer with the bilinear stress model by

$$
\sigma_{\mathrm{Al}, \text { plastic }}=\sigma_{\mathrm{y}}+\frac{\bar{E}_{\mathrm{Si}} h_{\mathrm{Si}}}{\bar{H}_{\mathrm{Al}} h_{\mathrm{Al}}+\bar{E}_{\mathrm{Si}} h_{\mathrm{Si}}} \bar{H}_{\mathrm{Al}}\left(\alpha_{\mathrm{Al}}-\alpha_{\mathrm{Si}}\right)\left(\Delta T-\Delta T_{\mathrm{y}}\right)
$$

where the hardening coefficient $H_{\mathrm{Al}}$ governs the stress increase in the plastic regime. The stress in the Si-layer in this regime can be described by

$$
\sigma_{\mathrm{Si}, \text { plastic }}=\sigma_{\mathrm{Al}, \mathrm{plastic}} \frac{h_{\mathrm{Al}}}{h_{\mathrm{Si}}}
$$

We can now insert Eqs. (4) and (5) into Eq. (1) and receive the energy release rates. The red lines in Fig. 8 show the calculated values for both the elastic and the elastic-plastic case. In the plastic regime the energy release rate is lowered, resulting in a higher temperature limit compared to the elastic case. From the intersection of $G_{\text {plastic }}$ and $G_{\mathrm{C}}$ in Fig. 8 we determine the processing range for interface debonding as $\Delta T_{\text {critical }}=187 \mathrm{~K}$ above room temperature. The critical values for both layers do not depend on the initial stress states prior to thermal cycling, as we assume that both samples are first heated up to the plastic regime, where the stress level is governed by the yield strength and not the residual stress, and then cooled down to room temperature.

Please note that our calculations are based on rather conservative assumptions. For the Al 99.7 layer, it was not possible to detect the yield strength during cooling and thus the material was treated as being in the elastic regime, what already results in the lowest possible processing limit. The yield strength of the high-purity layer was obtained by measuring XRD stress cooling down from $150{ }^{\circ} \mathrm{C}$. In reality the material yield strength decreases with increasing temperature. The critical limit then heavily depends on the strain hardening coefficient, which can be assumed as relatively high in this experiment compared to literature. With a hardening coefficient of $15 \mathrm{GPa}$, as suggested elsewhere, ${ }^{47}$ the critical processing temperature range for high-purity $\mathrm{Al}$ interface debonding is $\Delta T_{\text {critical }}=369 \mathrm{~K}$ above room temperature. A lower strain hardening coefficient of the $\mathrm{Al}$ would thus drastically increase the maximum temperature that can be applied during processing. Besides the material composition, the hardening coefficient $H_{\mathrm{Al}}$ also depends on the absolute processing temperature and the cooling rate. ${ }^{34}$ If it is not possible to avoid temperatures during processing that would lead to interface debonding, the introduction 
of a textured $\mathrm{Al}-\mathrm{Si}$ interface would be an option to expand the processing limits, as the critical energy release rate for debonding scales with the area of the interface. Hence, our results imply that MEMO-layers are wellsuited for low-temperature solar cell processing up to at least $210{ }^{\circ} \mathrm{C}$, depending on the particular properties of the Al layer, and are thus compatible with the proposed module level processing concept. In addition, we carried out some first experiments with dummy material that so far confirmed these findings.

\section{Cost estimation}

Given the significant deviation of the cell process in Fig. 7 from commercial solar cell concepts, a critical view on the expectable module costs is obligatory. We take the recent publication on sustainable future module costs by Goodrich et al., ${ }^{48}$ where a standard Si cell and three advanced cell concepts are compared, as a basis for our cost estimation. The model includes detailed price tags for every step in the module supply chain including costs of capital. An additional adjustment function takes into account the different efficiency potentials of the investigated cell technologies and allows for comparison on system level. To compare the MEMO concept within the model we have to make some assumptions and simplifications that are described in the following.

In the model, the required margins for every step in the supply chain are determined using corporate finance instruments. The technology routes have different requirements for manufacturing equipment, staffing and operating supplies, resulting in different required margins for every cell concept. As we do not have comparable corporate finance data for the MEMO concept, we assume the same profit per wafer as required for a wire-sawn wafer as sufficient. For cell and module processing we regard the highest relative margin of the other technologies as necessary for an effective business model. For cell processing, this results in a required margin of $22 \%$ as for a SHJ (Heterojunction with intrinsic thin layer/HIT) solar cell process. For module level processing the required margin is $20 \%$ as needed for an interdigitated back-contact (IBC) concept. By choosing the costliest option in each step, we minimize the risk of underestimating the required margin of every step in the supply chain for the MEMO concept.

Goodrich includes several variants of wafer thicknesses and $\mathrm{Si}$ demands and prices in his model. We calculate with a polysilicon feedstock price of $20 \$ / \mathrm{kg}^{2}{ }^{2}$ We further take into account diamond wire wafering for the non-kerfless cell concepts and assume the Si consumption to be $290 \mu \mathrm{m} / \mathrm{solar}$ cell, including $130 \mu \mathrm{m}$ kerf loss. This value represents the current technically feasible limit. ${ }^{1}$ For the Si thickness of the MEMO-layer we think positive and assume it to be $50 \mu \mathrm{m}$. This implies a stable exfoliation process with $40 \mu \mathrm{m}$ thick $\mathrm{Al}$ stressor layers as well as the repeated lift-off from the same thick substrate, which is a challenging task. The first demonstration of multiple spalling from an ingot was published by Bedell on GaAs using a Ni stressor layer. ${ }^{10}$ Results of three exfoliated Si-layers from the same substrate were published by Bellanger using a polymer stressor layer. ${ }^{21,49}$ We further assume for the cost estimation that wire and slurry consumables are not needed for exfoliation and therefore can be omitted. Beyond that we adopt the wafer production costs like utility, building, and maintenance without the consumables from the standard process, as a cost analysis for kerfless wafering by exfoliation at an industrial scale including the laser notch process is not available at present.

The evaporation of $40 \mu \mathrm{m} \mathrm{Al}$ with an in-line evaporator with a throughput of $75 \mathrm{MW} / \mathrm{y}$ adds a potentially unattainable cost penalty of $0.06 \$ / \mathrm{W}$ to the module costs, caused by the comparably high depreciation costs of the evaporation system and a declining uptime of the evaporator at higher evaporation rates. The material costs of the $\mathrm{Al}$ wire contribute with around $0.02 \$ / \mathrm{W}$ to the figure, based on an $\mathrm{Al}$ price of $13.65 \$ / \mathrm{kg}$, which is a reasonable price for $\mathrm{Al}$ high-purity wires. The $\mathrm{Al}$ yield rate is quite low, as only a quarter of the evaporated material is deposited on the sample in the end. At 100\% yield rate, the costs for the $\mathrm{Al}$ material would be less than $0.008 \$ / \mathrm{W}$, still based on the assumption that high-purity $\mathrm{Al}$ wires are used. For our cost estimation, we evaluate two scenarios: one with the evaporation costs included and one with only the material costs of the $\mathrm{Al}$ included to indicate the cost potential of the concept if an alternative metallization route is used. Alternatives to evaporation could base on a metal foil bonded to the substrate or on the evaporation of a thin $\mathrm{Al}$ layer and subsequent thickening via spray coating. Another option is the use of a two-material stressor layer of thin $\mathrm{Al}$ and a thicker and cheaper spin-on material.

On module level we assume a glass back pane without anti-reflection coating, which lowers the cost of the rear side glass pane by a factor of 1.6 compared to the front glass. Furthermore we use a thin silicone $(60 \mu \mathrm{m})$ rear encapsulation layer to bond the MEMO cells to the glass. Both components are more robust to the front side processing steps that are carried out after bonding the bilayer to the rear substrate than a plastic backsheet and other encapsulation materials like ethylene-vinyl acetate (EVA). ${ }^{50} \mathrm{We}$ estimate the costs of the silicone encapsulant to be $20 \$ / \mathrm{kg}$, which results in layer costs per area of $27 \%$ compared to an EVA layer. The front side is encapsulated with a single EVA sheet and high-quality glass with anti-reflective coating. The module cost portion of the MEMO process flow is slightly increased compared to standard concepts where a plastic back sheet and complete EVA encapsulation are used. 
All other process step costs as well as the efficiency potentials for the cell concepts are adopted from Goodrich et al. We add up the different cost portions to calculate the respective price in $\$ / \mathrm{W}$. The different cell concepts result in different final module efficiencies. We include the different cell-to-module losses of the concepts that were partly unaccounted for in the original paper in our calculations and the case of a 20\% PERC module which we believe is in the line of sight according to Ref. 1. In a last step, we normalize the prices to the standard c-Si module price to access the relative price advantages of the different cell and module concepts.

The overall result is shown in Fig. 9: we end up with lower costs on module level compared to all other cell concepts for a MEMO device with $20 \%$ estimated module conversion efficiency if we exclude the $\mathrm{Al}$ evaporation costs. The expected module costs are $36 \%$ lower than the costs of an Al-back-surface-field-module and $11-15 \%$ lower than the costs for the advanced cell concepts from Ref. 48. Compared to a $20 \%$ PERC module, the possible cost advantage drops down to only $3 \%$. With the evaporation costs included, the costs of a MEMO module are still competitive compared to SHJ and IBC cell concepts but not to the 20\% PERC module, which exhibits slightly lower costs. An advantage over the 20\% PERC module can only be obtained if the Al deposition costs can be brought below $2 \mathrm{ct} / \mathrm{Wp}$. The relatively small price advantage is a sobering result for implementing the process into the industry. The savings only pay off, if the cell process can be kept simple and a repeated lift-off from the same substrate can be applied, as assumed here. But even if those challenges are solved, the cost savings compared to PERC modules, which are already evaluated at industrial scale, could be too low to justify the risk connected to the implementation of a new technology.

From the diagram it is visible that all possible cost savings are solely caused by the lowered wafer costs due to the reduced $\mathrm{Si}$ consumption. Further price reductions in the conventional wafer production would lead to an even smaller cost advantage for the kerfless process. Advancements in the ingot production would be passedthrough as in any ingot-based kerfless wafering scenario, however also reducing the MEMO cost advantage. On the other hand, the module and cell cost portions of the MEMO process are not higher than for the other projected future technologies (except for PERC), so that the exfoliation approach will stay at the same level of competitiveness if the assumed efficiencies can be reached.

The choice of an appropriate alternative metal could give an advantage over $\mathrm{Al}$ by reducing the minimum thickness of the stressor layer that is needed for lift-off. A candidate is nickel $(\mathrm{Ni})$, which is used by some other groups ${ }^{10-13}$ for exfoliation. If we conduct the calculations for the layer thickness ratio in Fig. 6 for instance with nickel $\mathrm{Ni}$ instead of $\mathrm{Al}$, an $11 \mu \mathrm{m}$ thick Ni layer would also lead to same Si layer thickness spalled from a $2500 \mu \mathrm{m}$ thick substrate as a $40 \mu \mathrm{m}$ thick Al layer. On the other hand, $\mathrm{Ni}$ is much more expensive than $\mathrm{Al}$ and it is difficult to deposit compact Ni layers thicker than a few micrometers. The material costs of a $11 \mu \mathrm{m} \mathrm{Ni} \mathrm{layer}$ would already add $0.01 \$ / \mathrm{W}$ to the module costs, if only the wholesale price of untreated $\mathrm{Ni}(\sim 20 \$ / \mathrm{kg})$ is considered. This position will be increased by additional costs for material refining, a proper metallization technique,

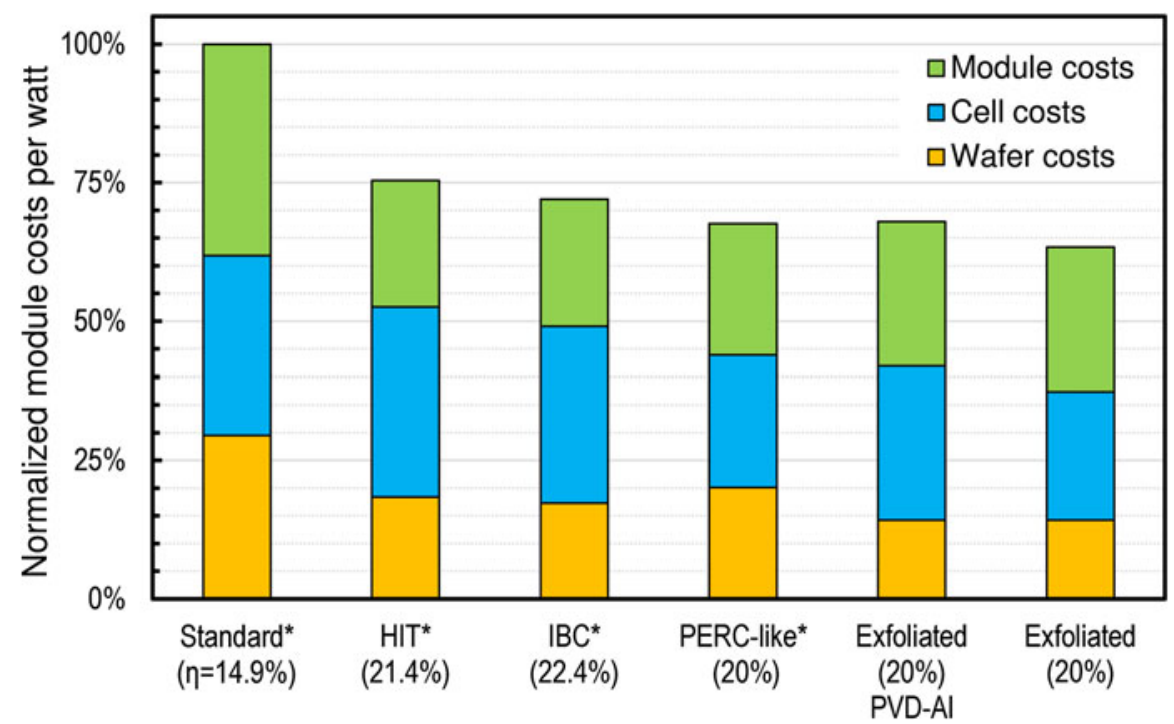

FIG. 9. Efficiency-adjusted module prices normalized to standard p-type solar cells for exfoliated MEMO/HySi cells and three other advanced cell concepts. The parenthesized values for $\eta$ refer to estimated module efficiencies. For details on the alternative technology concepts see the reference by Goodrich et al. ${ }^{48}$ 
and material losses during the process. Thus, we do not consider $\mathrm{Ni}$ as a convenient stressor layer material for a MEMO-like Si solar cell concept.

Another drawback of the proposed MEMO process could be the additional research and development resources that have to be spent to refine the processing steps and adapt them to the special challenges of the concept like the curved bilayer that has to be flatly encapsulated. From this point of view, one might think of using the exfoliation process only for wafering, removing the stressor layer afterward, and applying a more established cell process like PERC to the exfoliated, thin wafer. This approach actually only pays off if the price for poly-Si is high enough. The Si savings have to compensate for the Al evaporation and an additional wet-etching step for the Al stressor layer removal. In our cost model, this wafering approach yields a financial benefit of $0.01-0.02 \$ / \mathrm{W}$ given a poly-Si price of $20 \$ / \mathrm{kg}$. The benefit shrinks with lower Si prices. For a poly-Si of $16.5 \$ / \mathrm{kg}$ or less, classical wafering is actually cheaper than the kerfless process if the metal layer is not kept as a functional layer. As the poly-Si price is assumed to level off somewhere between 16 and $20 \$ / \mathrm{kg}$ for the next years, ${ }^{1,2}$ we rate this approach as not competitive to both the standard process and the MEMO process with a re-integrated functional stressor layer.

Using a polymer layer instead of $\mathrm{Al}$ could give an additional cost advantage, if a suitable and cheap polymer can be found. Assuming a polymer thickness of $400 \mu \mathrm{m}$, which is a reasonable thickness for the exfoliation of a $50 \mu \mathrm{m}$ thick $\mathrm{Si}$ foil, ${ }^{51}$ the polymer price has to be less than $12.50 \$ / \mathrm{L}$ to offer a price advantage over the proposed $\mathrm{Al}$ process. We think that for today this value is hard to underprice for the highly specialized polymers that are commonly applied for the lift-off. Of course, future developments in polymer production might help to pave the way to more economic and competitive stressor layers from non-metallic materials. From today, we think that $\mathrm{Al}$ is an excellent choice of material for exfoliation of thin Si wafers and their integration into solar cells. The attractiveness of exfoliation at all, however, is highly dependent on the achievable cost advantage over standard techniques. The ongoing improvements in the efficiency of PERC modules that rely on a comparatively lean and simple cell processing route will hamper the introduction of advanced c-Si solar cell concepts like MEMO, as the expected cost advantages might not be sufficient, at least at the currently assumed poly-Si prices within the next years.

\section{SUMMARY}

We discussed the production of thin crystalline Si solar cell absorber layers utilizing evaporated $\mathrm{Al}$ as stressor layer. The MEMO bilayers show excellent electronical properties. We investigate the mechanical properties of the $\mathrm{Al}$ stressor layer and find them applicable to the exfoliation process. A feasible module level processing concept is discussed in the paper. We determine the processing limits for the exfoliated Al-Si-bilayers and find that exfoliation with $40 \mu \mathrm{m}$ thick $\mathrm{Al}$ layers is possible. We show that the layers are compatible with SHJ solar cell processing and withstand the typically applied processing temperatures around $200{ }^{\circ} \mathrm{C}$. We analyze the expected costs of the proposed route and find a potential for cost savings of 3-36\% comparing the kerfless exfoliation concept with other projected future cell concepts based on classically produced wafers. We also find that the advantage over high-efficiency PERC cells from standard Si wafers, which represent an already established technological route, might not be enough to justify the introduction of a new cell and module concept, even if cheap and widely available $\mathrm{Al}$ is used for the stressor layer.

\section{ACKNOWLEDGMENTS}

The authors thank Alwina Knorr, Rene Berger, Daniel Münster, Frank Heinemeyer, and David Sylla for valuable help with the sample preparation and Jan-Hendrik Petermann and Chistopher Kranz for fruitful discussions on cell concepts and the cost model. This work was supported by the Federal Ministry for Environment, Nature Conservation, and Nuclear Safety and the Federal Ministry for Economic Affairs and Energy under the contract FKZ 0325461 (MEMO), and by the state of Lower Saxony.

\section{REFERENCES}

1. International Technology Roadmap for Photovoltaic (ITRPV) (SEMI PV GROUP, Berlin, Germany, 2015) www.itrpv.net (accessed May 25, 2015).

2. C. Yisng: Energy Trend PV (2014) http://pv.energytrend.com/ price/20140103-6007.html (accessed January 7, 2014).

3. M. Bruel: Silicon on insulator material technology. Electron. Lett. 31(14), 1201 (1995)

4. F. Henley, S. Kang, Z. Liu, L. Tian, J. Wang, and Y-L. Chow: Beam-induced wafering technology for kerf-free thin PV manufacturing. Presented at the 34th IEEE Photovoltaic Specialists Conference, Philadelphia, 2009; p. 1718.

5. R. Brendel and M. Ernst: Macroporous $\mathrm{Si}$ as an absorber for thinfilm solar cells. Phys. Status Solidi RRL 4(1-2), 40 (2010).

6. R. Brendel: A novel process for ultrathin monocrystalline silicon solar cells on glass. Presented at the 14th European Photovoltaic Solar Energy Conference, Barcelona, Spain, 1997; p. 1354.

7. G.J. Hayes and B.M. Clemens: Rapid lift-off of epitaxial thin films. J. Mater. Res. 28(18), 2564 (2013).

8. M. Tanielian, S. Blackstone, and R. Lajos: A new technique of forming thin free standing single-crystal films. J. Electrochem. Soc. 132(2), 508 (1985).

9. F. Dross, J. Robbelein, B. Vandevelde, E. van Kerschaver, I. Gordon, G. Beaucarne, and J. Poortmans: Stress-induced largearea lift-off of crystalline Si films. Appl. Phys. A 89(1), 149 (2007). 
10. S.W. Bedell, D. Shahrjerdi, B. Hekmatshoar, K. Fogel, P. Lauro, J.A. Ott, N.E. Sosa Cortes, and D. Sadana: Kerf-less removal of $\mathrm{Si}, \mathrm{Ge}$, and III-V layers by controlled spalling to enable low-cost PV technologies. IEEE J. Photovoltaics 2(2), 141 (2012).

11. S.W. Bedell, K. Fogel, P. Lauro, D. Shahrjerdi, J.A. Ott, and D. Sadana: Layer transfer by controlled spalling. J. Phys. D: Appl. Phys. 46(15), 152002 (2013).

12. R.A. Rao, L. Mathew, S. Saha, S. Smith, D. Sarkar, R. Garcia, R. Stout, and A. Gurmu: A novel low cost $25 \mu \mathrm{m}$ thin exfoliated monocrystalline Si solar cell technology. Presented at the 37th IEEE Photovoltaic Specialists Conference, Seattle, 2011; p. 1504.

13. Y. Kwon, C. Yang, S-H. Yoon, H-D. Um, J-H. Lee, and B. Yoo: Spalling of a thin Si layer by electrodeposit-assisted stripping. Appl. Phys. Express 6(11), 116502 (2013).

14. Z. Suo and J.W. Hutchinson: Steady-state cracking in brittle substrates beneath adherent films. Int. J. Solids Struct. 25(11), 1337 (1989).

15. R.A. Rao, L. Mathew, D. Sarkar, S. Smith, S. Saha, R. Garcia, R. Stout, A. Gurmu, and M. Ainom: A low cost kerfless thin crystalline $\mathrm{Si}$ solar cell technology. Presented at the 38th IEEE Photovoltaic Specialists Conference, Austin, 2012; p. 1837.

16. A. Masolin, E. Simoen, J. Kepa, and A. Stesmans: Defects in Si foils fabricated by spalling at low temperature: Electrical activity and atomic nature. J. Phys. D: Appl. Phys. 46(15), 155501 (2013).

17. R. Martini, J. Kepa, M. Debucquoy, V. Depauw, M. Gonzalez, I. Gordon, A. Stesmans, and J. Poortmans: Thin silicon foils produced by epoxy-induced spalling of silicon for high efficiency solar cells. Appl. Phys. Lett. 105(17), 173906 (2014).

18. R.A. Sinton: Quasi-steady-state photoconductance, a new method for solar cell material and device characterization. Presented at the 25th IEEE Photovoltaic Specialists Conference, Washington, D.C., 1996; p. 457.

19. S. Saha, M.M. Hilali, E.U. Onyegam, D. Sarkar, D. Jawarani, R.A. Rao, L. Mathew, R.S. Smith, D. Xu, U.K. Das, B. Sopori, and S.K. Banerjee: Single heterojunction solar cells on exfoliated flexible $\sim 25 \mu \mathrm{m}$ thick mono-crystalline silicon substrates. Appl. Phys. Lett. 102(16), 163904 (2013).

20. S. Schönfelder, O. Breitenstein, S. Rissland, R. de Donno, and J. Bagdahn: Glue-cleave: Kerfless wafering for silicon wafers with metal gluing and removable interface. In Proceedings of the 22nd Workshop on Crystalline Silicon Solar Cells \& Modules: Materials and Processes, B. Sopori and R. Sinton ed.; Golden: Vail, CO, 2012; p. 208.

21. P. Bellanger, M.C. Brito, D. Pera, I. Costa, G. Gaspar, R. Martini, M. Debucquoy, and J.M. Serra: New stress activation method for kerfless silicon wafering using $\mathrm{Ag} / \mathrm{Al}$ and epoxy stress-inducing layers. IEEE J. Photovoltaics 4(5), 1228 (2014).

22. J.E. Hatch: Aluminum: Properties and Physical Metallurgy (ASM International, Russel, OH, 1984); p. 6.

23. A. Masolin, P-O. Bouchard, R. Martini, and M. Bernacki: Thermo-mechanical and fracture properties in single-crystal silicon. J. Mater. Sci. 48(3), 979 (2013).

24. J. Hensen, R. Niepelt, S. Kajari-Schroder, and R. Brendel: Directional heating and cooling for controlled spalling. IEEE $J$ Photovoltaics 5(1), 195 (2015).

25. F. Heinemeyer, C. Mader, D. Münster, T. Dullweber, N.P. Harder, and R. Brendel: In-line high-rate thermal evaporation of aluminium as a novel industrial solar cell metallization scheme. In Proceedings of the 2nd Workshop on Metallization for Crystalline Silicon Solar Cells, J. Hoornsta, G. Schubert, and G. Beaucarne ed.; University of Konstanz: Konstanz, Germany, 2010; p. 48.

26. R. Niepelt, J. Hensen, A. Knorr, V. Steckenreiter, S. KajariSchröder, and R. Brendel: High-quality exfoliated crystalline silicon foils for solar cell applications. Energy Procedia 55, 570 (2014).
27. S. Kajari-Schröder, J. Hensen, R. Niepelt, and R. Brendel: Kerfless wafering by mechanically induced spallation-Observation of the process evolution with digital image correlation. Presented at the 6th World Conference on Photovoltaic Energy Conversion, Kyoto, Japan, 2014; p. J1ThO.7.3.

28. K. Ramspeck, K. Bothe, J. Schmidt, and R. Brendel: Combined dynamic and steady-state infrared camera based carrier lifetime imaging of silicon wafers. J. Appl. Phys. 106(11), 114506 (2009).

29. H. Schlangenotto, H. Maeder, and W. Gerlach: Temperature dependence of the radiative recombination coefficient in silicon. Phys. Status Solidi A 21(1), 357 (1974).

30. A. Richter, S.W. Glunz, F. Werner, J. Schmidt, and A. Cuevas: Improved quantitative description of Auger recombination in crystalline silicon. Phys. Rev. B 86(16), 5202 (2012).

31. E. Macherauch and P. Müller: Zur Eigenspannungsausbildung bei einer Al-Legierung und bei Reinstaluminium. Naturwissenschaften 44(14), 389 (1957).

32. J.M. Gere: Mechanics of Materials, 6th ed. (Brooks/Cole, Belmont, CA, 2004).

33. A.G. Evans and J.W. Hutchinson: The thermomechanical integrity of thin films and multilayers. Acta Metall. Mater. 43(7), 2507 (1995).

34. H. Shi, A.J. McLaren, C.M. Sellars, R. Shahani, and R. Bolingbroke: Constitutive equations for high temperature flow stress of aluminium alloys. Mater. Sci. Technol. 13, 210 (1997).

35. M. Bauser, G. Sauer, and K. Siegert: Extrusion, 2nd ed. (ASM International, Russel, OH, 2006).

36. S. Bader, E.M. Kalaugher, and E. Arzt: Comparison of mechanical properties and microstructure of $\mathrm{Al}(1 \mathrm{wt} . \% \mathrm{Si})$ and $\mathrm{Al}(1 \mathrm{wt} . \% \mathrm{Si}$, 0.5 wt.\%Cu) thin films. Thin Solid Films 263(2), 175 (1995).

37. M. Kerr, P. Campbell, and A. Cuevas: Lifetime and efficiency limits of crystalline silicon solar cells. Presented at the 29th IEEE Photovoltaic Specialists Conference, New Orleans, 2002; p. 438.

38. A. Richter, M. Hermle, and S.W. Glunz: Reassessment of the limiting efficiency for crystalline silicon solar cells. IEEE $J$. Photovoltaics 3(4), 1184 (2013).

39. R. Brendel, J.H. Petermann, D. Zielke, H. Schulte-Huxel, M. Kessler, S. Gatz, S. Eidelloth, R. Bock, E. Garralaga Rojas, J. Schmidt, and T. Dullweber: High-efficiency cells from layer transfer: A first step toward thin-film/wafer hybrid silicon technologies. IEEE J. Photovoltaics 1(1), 9 (2011).

40. J.H. Petermann, H. Schulte-Huxel, V. Steckenreiter, S. KajariSchroder, and R. Brendel: Principle of module-level processing demonstrated at single a-Si:H/c-Si heterojunction solar cells. IEEE J. Photovoltaics 4(4), 1018 (2014).

41. J. Govaerts, J. Robbelein, M. Gonzalez, I. Gordon, K. Baert, I. de Wolf, F. Bossuyt, S. van Put, and J. Vanfleteren: Developing an advanced module for back-contact solar cells. IEEE Trans. Compon., Packag., Manuf. Technol. 1(3), 1319 (2011).

42. J.C. Kim and S.K. Cheong: I-V curve characteristics of solar cells on composite substrate unsder mechanical loading. J. Mech. Sci. Technol. 28(5), 1691 (2014).

43. D. Xu, P.S. Ho, R.A. Rao, L. Mathew, S. Smith, S. Saha, D. Sarkar, C. Vass, and D. Jawarani: Mechanical strength and reliability of a novel thin monocrystalline silicon solar cell. Presented at the IEEE International Reliability Physics Symposium, Anaheim, 2012; p. 4A.3.1.

44. V. Tvergaard and J.W. Hutchinson: Toughness of an interface along a thin ductile layer joining elastic solids. Philos. Mag. A 70 (4), 641 (1994).

45. A. Volinsky, N. Moody, and W. Gerberich: Interfacial toughness measurements for thin films on substrates. Acta Mater. 50(3), 441 (2002).

46. Y. Wei and J.W. Hutchinson: Nonlinear delamination mechanics for thin films. J. Mech. Phys. Solids 45(7), 1137 (1997). 
47. Y.Y. Hu and W.M. Huang: Elastic and elastic-plastic analysis of multilayer thin films: Closed-form solutions. J. Appl. Phys. 96(8), 4154 (2004).

48. A. Goodrich, P. Hacke, Q. Wang, B. Sopori, R. Margolis, T.L. James, and M. Woodhouse: A wafer-based monocrystalline silicon photovoltaics road map: Utilizing known technology improvement opportunities for further reductions in manufacturing costs. Sol. Energy Mater. Sol. Cells 114, 110 (2013).

49. P. Bellanger, P-O. Bouchard, M. Bernacki, and J. Serra: Room temperature thin foil SLIM-cut using an epoxy paste:
Experimental versus theoretical results. Mater. Res. Express 2 (4), 046203 (2015).

50. V. Steckenreiter, R. Horbelt, D.N. Wright, M. Nese, and R. Brendel: Qualification of encapsulation materials for modulelevel-processing. Sol. Energy Mater. Sol. Cells 120, 396-401 (2014).

51. A. Masolin: Fabrication and characterization of ultra-thin silicon crystalline wafers for photovoltaic applications using a stressinduced lift-off method. Ph.D. Thesis, KU Leuven, Faculty of Engineering, Leuven, BE, 2012. 